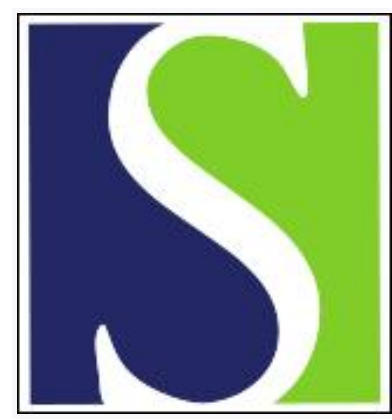

Scand J Work Environ Health 2008;34(6):463-470

https://doi.org/10.5271/sjweh.1293

Issue date: 00 Dec 2008

Long-term follow-up study of mortality and the incidence of cancer in a cohort of workers at a primary aluminum smelter in Sweden

by Björ O, Damber L, Edström C, Nilsson T

Affiliation: Department of Radiation Science, Oncology, Umeå University, SE-901 85 Umeå, Sweden. ove.bjor@oc.umu.se

Refers to the following texts of the Journal: 1999;25(6):473-483 1999;25(1):24-32 1999;25(3):207-214

The following article refers to this text: 2019;45(3):217-238

Key terms: aluminum smelter; cancer; cancer incidence; Cox regression; follow-up study; incidence; mortality; occupation; primary aluminum smelter; standardized incidence ratio; standardized mortality ratio; Sweden; worker

This article in PubMed: www.ncbi.nlm.nih.gov/pubmed/19137208 


\title{
Long-term follow-up study of mortality and the incidence of cancer in a cohort of workers at a primary aluminum smelter in Sweden
}

\author{
by Ove Björ, BSc, ${ }^{1}$ Lena Damber, PhD, ${ }^{1}$ Clarence Edström, BSc, ${ }^{2}$ Tohr Nilsson, PhD ${ }^{2}$
}

\begin{abstract}
Björ 0, Damber L, Edström C, Nilsson T. Long-term follow-up study of mortality and the incidence of cancer in a cohort of workers at a primary aluminum smelter in Sweden. Scand J Work Environ Health 2008;34(6):463-470.

Objectives Previous studies on mortality and the incidence of cancer among workers at primary aluminum smelters have produced conclusive results indicating an elevated risk of bladder cancer. An increased risk of lung cancer has also been reported several times. The objective of this study was to examine mortality and the incidence of cancer at a Swedish aluminum smelter when different neighboring reference populations were used to evaluate any relationships to the length of employment.

Methods A historical cohort-comprised of 2264 male nonoffice workers employed from 1942 on and tracked up to the year 2000 - was examined. With the use of three reference populations for mortality and four for cancer incidence, standardized mortality and incidence ratios were calculated, together with hazard ratios derived from Cox regression models.

Results This study showed an excess risk of mortality due to chronic obstructive lung disease, mental disorders, and diseases of the digestive system among the short-term workers. An elevated risk of cancer was found for the lungs, central nervous system, and esophagus. The highest lung cancer risk was observed for the workers employed for $\geq 10$ years in the factory when they were compared with the reference group from northern Sweden (standardized incidence ratio $1.99,95 \%$ confidence ratio $1.21-3.07$ ).

Conclusions The results support previous studies that demonstrated an excess risk of lung cancer, but, in contrast to the results of most studies, cancer of the central nervous system was also elevated. This study did not, however, verify an association between this type of exposure and cancer of the urinary organs.
\end{abstract}

Key terms Cox regression; occupation; standardized incidence ratio, standardized mortality ratio.

Work in the primary aluminum industry is associated with a wide range of exposures, several of which may be hazardous to the health of workers. Such exposures include hydrogen fluoride and fluorides of aluminum and sodium (eg, chryolite), aluminas (ie, aluminum oxides), carbon monoxide, sulfur dioxide, coal-tar-pitch volatiles [including polycyclic aromatic hydrocarbons (PAH), soot, coke and pitch dusts], crystalline silica, refractory ceramic fibers and asbestos, alloying metals (eg, manganese, copper), purifying agents (eg, chlorine), trace elements (eg, beryllium), and welding fumes and diesel exhaust gases. In addition, there are static and alternating magnetic fields, heat, and noise. Coarse, fine, and ultrafine aerosols are present. Short aluminous fibers (fluoride and oxide) have also been recorded (1-5). The International Agency for Research on Cancer (IARC) has classified aluminum production as carcinogenic to humans. Coal-tar pitch, benzo(a)pyrene (a PAH), crystalline silica, asbestos, and beryllium are individual agents occurring in this work environment, classified by IARC as carcinogenic to humans. Some other PAH, diesel exhausts, welding fumes, refractory ceramic fibers, and alternating magnetic fields (extremely low frequency) are classified as probably or possibly carcinogenic (6).

Previous epidemiologic studies of the mortality of primary aluminum workers have generally shown lower risks in association with all causes when these workers were compared with reference populations, this finding possibly being explained by the healthy worker effect (7-12). Although an excess risk of mortality was uncommon in these studies, it has been found for asthma, emphysema and bronchitis $(8,11,13)$, respiratory diseases (11), tumors (11), accidents (10), and liver cirrhosis (10). Friesen et al (14) found a moderate association between

1 Department of Radiation Science, Oncology, Umeå University, Umeå, Sweden.

2 Department of Occupational and Environmental Medicine, Sundsvall Hospital, Sundsvall, Sweden.

Reprint requests to: Ove Björ, Department of Radiation Science, Oncology, Umeå University, SE-901 85 Umeå, Sweden. [E-mail: ove.bjor@oc.umu.se] 
exposure to PAH and acute myocardial infarction for aluminum smelter workers. As regards the incidence of cancer, the most consistent finding in previous studies has been an increased incidence of bladder cancer $(8$, 14-20). Cancer of the lungs $(11,14,17,21,22)$, pancreas (18), kidneys $(15,17,18)$, lymphoma (17), stomach (17), and brain (23) has also been found to be associated with workers in aluminum plants, but these findings are less consistent. In 1999, Carstensen et al (24) measured high levels of PAH in the blood and urine of a sample of potroom workers, as well as high levels in the air at the same smelter examined in this study, but they found no increase in aromatic DNA (deoxyribonucleic acid) adducts when the exposed workers were compared with unexposed workers.

The objective of this study was to examine the occurrence of mortality and the incidence of cancer at a Swedish aluminum smelter with the use of different neighboring populations as reference and to evaluate any relationships to the length of employment.

\section{Study population and methods}

The study plant is the only primary aluminum smelter in Sweden; it is situated in the county of Västernorrland on the northeastern coast. Production has expanded 50-fold since it opened in 1942. Both prebake and Söderberg technologies have been used, as illustrated in figure 1 . The closed prebake technique in unit 1 gives the cleanest manufacturing process. The techniques used earlier should not differ as much in respect to the work environment. Important changes in the factory and work routines potentially affecting exposures were initiated at the end of 1970. Among the earliest was the introduction

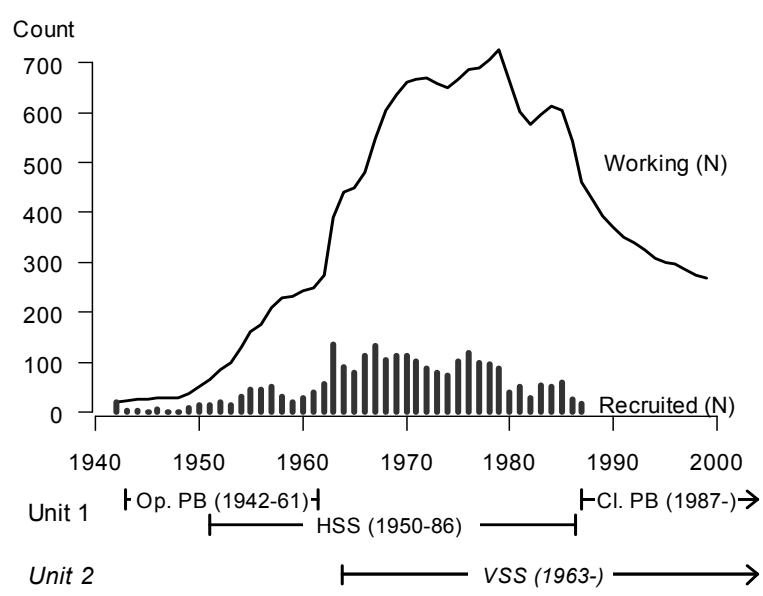

Figure 1. Number of recruitments to the plant in the cohort and the number still employed per year. The horizontal bars represent open prebake (Op PB), horizontal stud Söderberg (HSS), vertical stud Söderberg (VSS), and closed prebake (CI PB) technologies. of single-use respirators, computerized process control in unit 2, and low-pitch anode paste in unit 2.

A cohort of workers was constructed from company records that contained the dates of the beginning and end of employment, including any multiple periods of employment. Because each cohort member had either their occupation or department registered, it was possible to identify office workers and exclude them from the study cohort. Only male workers employed for $>6$ months were included. All of the workers employed between 1942 and 1987 were eligible for the cohort, and their employment was tracked until 2000. Among the 4841 workers in the original cohort, 365 were excluded because of missing information on employment dates, 1878 were excluded because they were employed for less than 6 months, 318 lacked unique identification information, 4 had a diagnosis prior to their first employment, and 9 were employed before production officially started at the plant in 1942. Most of the short-term workers were substitutes for workers on vacation, workers on the sick list, and workers doing military service. The final study cohort consisted of 2264 male nonoffice workers and represents a study base of 70856 person-years. The average age at first employment was 29.5 years, and the average number or years employed was 8.4. Most of the workhours originated from the mid-1960s to the mid-1980s; during this time only Söderberg pots were in operation (figure 1).

The cohort was linked with the Swedish cancer register for the period 1958 to 2005 using the 10-digit personal identification numbers of the workers as the identifier. Vital status was examined from 1952 to 2004, and the possible date of death and the underlying cause of death were determined from the Swedish Cause of Death Register. All analyses of the incidence of cancer and mortality were based on the code of the International Classification of Diseases, seventh revision (ICD-7), and only diagnoses coded as nonbenign were included. Later versions of the ICD were translated to ICD-7. Information on emigration was collected from a population register, and the follow-up time was stopped as of the date of emigration. Information on smoking was not available for this study.

To determine whether there was an excess risk of mortality or cancer, we calculated the standardized mortality ratios (SMR) and standardized incidence ratios (SIR); the ratios were standardized for age and follow-up year using three reference populations for mortality and four for the incidence of cancer. The factory is located close to Sundsvall, which is one of the largest cities in northern Sweden. Northern Sweden consists of the counties of Jämtland, Västernorrland, Västerbotten, and Norrbotten and is a rural area with approximately $12 \%$ of the population in Sweden in an area covering more than half of the country. The differences in socioeconomic status, 
lifestyle, and environmental influences between populations are reflected in health status, a condition that leads to standardized ratio levels sometimes being dependent on the choice of the reference population. Using different reference populations furnishes knowledge of this variation and strengthens conclusions. Reference populations from Sweden, northern Sweden, and the county of Västernorrland located in northern Sweden were used both for mortality and the incidence of cancer.

The seven largest municipalities in northern Sweden were used as another reference for the incidence of cancer because of socioeconomic similarities with the municipality of Sundsvall, where the factory is located. It was not possible to establish a reference group for mortality due to different geographic groupings in the mortality and demographic registers. The standardized mortality and incidence ratios were calculated for groups of diagnoses with more than 20 cases for mortality and more than 10 for cancer. Pancreatic cancer and cancer of the esophagus were included in order to compare the results with those from previous studies of the pancreas (18) and stomach (17). Due to the limited population size, reference rates from the county of Västernorrland were used only when the number of observed cases was more than $40 ; 95 \%$ confidence intervals $(95 \% \mathrm{CI})$ for the standardized mortality and incidence ratios were calculated on the assumption that the number of observed cases fitted a Poisson distribution (25). The standardized mortality ratio was calculated by excluding the first 6 months of employment in order to take into account minimum time for workers to be eligible for inclusion in the cohort and for the standardized incidence ratio as a minimum latency time. The effect of latency was examined by examining time lags of $5,10,20$, and 30 years from first employment. The standardized mortality and incidence ratios, based on cumulative employment times of 0.5 to $\leq 2$ years, 2 to $\leq 10$ years, and $>10$ years were calculated using northern Sweden as the reference population if the total number of cases was more than 15. A Cox regression analysis was performed to examine the effect of cumulative employment time within the cohort and to facilitate valid trend tests. In order to control any possible age effect properly, age was used as the time axis by left censoring at the age of first employment in the Cox regression analysis. Cumulative employment times, represented by 0.5 to $\leq 2$ years, 2 to $\leq 10$ years, and $>10$ years, were included in the model as time-dependent categorical variables, and trend tests were performed by assigning scores using the mean employment time from the respective group and including it as a continuous variable. All of the results were adjusted for year of first employment as a continuous variable.

All of the statistical analyses were conducted using SAS statistical software (release 9.1.3; SAS Institute, Cary, NC, USA).

\section{Results}

The results for mortality are presented in table 1 . The rates of various causes of death that were significantly higher in the cohort than in the reference populations were recorded for mental disorders, chronic obstructive lung disease, and diseases of the digestive system. The latter two only applied to workers with employment times of 0.5-2 years. The Cox model showed that there were statistically lower risks for chronic obstructive lung disease and diseases of the digestive system for longterm workers than for workers employed for $0.5-2$ years. Of the 34 cases of death as a result of mental disorders, 27 were related to alcohol. The risk of myocardial infarction was significantly lower than the expected value when the county of Västernorrland was used as the reference but not lower than when the other reference populations were used.

When the effect of a lag time of 5, 10, 20, or 30 years was used, no consistent association was found between the standardized mortality ratio and lag time, except for diseases of the digestive system, for which the estimated standardized mortality ratio exhibited a monotonous increase as the lag times increased. For diseases of the digestive system, the standardized mortality ratios were 1.20 (95\% CI 0.75-1.81), 1.30 (95\% CI 0.81-1.97), 1.35 (95\% CI 0.79-2.16), and 1.44 (95\% CI 0.69-2.66). The same monotonous increase in the standardized mortality ratios with longer lag times was observed when Sweden was used as the reference population.

The cancer incidence results are presented in table 2 . [The results using Västernorrland as the reference population are only mentioned in the text and do not appear in the table]. Significantly higher rates in the cohort, compared with in the reference populations, were observed for lung cancer, cancers of the central nervous system, and esophageal cancer. The only observed significant excess risk for cumulative employment time with respect to the standardized incidence ratio was for lung cancer among the workers with $\geq 10$ years of employment. The corresponding estimates of the standardized incidence ratios were 1.56 (95\% CI 0.95-2.41) with the Swedish reference population, 1.82 (95\% CI 1.11-2.81) with the seven municipalities as reference, and $1.75(95 \% \mathrm{CI}$ 1.07-2.72) with the Västernorrland reference group. The Cox model showed that there were significantly higher risks for all cancers and prostate cancer among the shortterm workers of the aluminum smelter.

The standardized incidence ratios incorporating a lag time of 5, 10, 20, or 30 years had no clear effect on the risk, except for lung cancer, for which the estimates of the standardized incidence ratio decreased as the lag times increased. With northern Sweden as the reference, the incidence ratio for lung cancer for the respective lag times was 1.65 (95\% CI 1.18-2.25), 1.52 
Table 1. Standardized mortality ratios (SMR) and 95\% confidence invervals $(95 \% \mathrm{Cl})$ for death among the workers in the aluminum production industry, calculated with the use of three different reference populations, and the hazard ratios and their $95 \%$ confidence intervals, calculated with trend tests from Cox regression models using 0.5 to $\leq 2$ years of cumulative employment time as a reference.

\begin{tabular}{|c|c|c|c|c|c|c|c|c|c|c|}
\hline \multirow[t]{2}{*}{ Cause of death ${ }^{\mathrm{a}}$} & \multirow[t]{2}{*}{$\begin{array}{l}\text { Cases } \\
\text { (N) }\end{array}$} & \multicolumn{2}{|c|}{ Northern Sweden } & \multicolumn{2}{|c|}{ Sweden } & \multicolumn{2}{|c|}{$\begin{array}{c}\text { County of } \\
\text { Västernorrland }\end{array}$} & \multirow[t]{2}{*}{$\begin{array}{c}\text { Hazard } \\
\text { ratio }\end{array}$} & \multirow[t]{2}{*}{$95 \% \mathrm{Cl}$} & \multirow[t]{2}{*}{$\begin{array}{l}\text { Test for } \\
\text { trend }\end{array}$} \\
\hline & & SMR & $95 \% \mathrm{Cl}$ & SMR & $95 \% \mathrm{Cl}$ & SMR & $95 \% \mathrm{Cl}$ & & & \\
\hline \multicolumn{11}{|l|}{ All causes } \\
\hline Any years & 650 & 1.01 & $0.93-1.09$ & 1.05 & $0.97-1.13$ & 1.04 & $0.97-1.13$ &.. & .. & .. \\
\hline $0.5-\leq 2$ years & 197 & 1.14 & $0.98-1.31$ &.. & .. &.. & .. & 1.00 & .. & .. \\
\hline $2-10$ years & 206 & 0.98 & $0.85-1.13$ & .. & .. & .. & .. & 0.83 & $0.63-1.10$ & .. \\
\hline$>10$ years & 247 & 0.95 & $0.83-1.07$ & .. & .. & .. & .. & 0.73 & $0.55-0.96$ & $P=0.07$ \\
\hline \multicolumn{11}{|c|}{ Tumors (140-239) } \\
\hline Any years & 170 & 1.16 & $0.99-1.35$ & 1.09 & $0.94-1.27$ & 1.08 & $0.92-1.26$ &.. & .. & .. \\
\hline $0.5-\leq 2$ years & 50 & 1.26 & $0.94-1.67$ &.. & .. & .. & .. & 1.00 & .. & .. \\
\hline $2-10$ years & 52 & 1.13 & $0.85-1.49$ & .. &.. & .. & .. & 0.91 & $0.62-1.35$ & .. \\
\hline$>10$ years & 68 & 1.11 & $0.87-1.41$ & .. & .. & .. & .. & 0.90 & $0.62-1.32$ & $P=0.74$ \\
\hline \multicolumn{11}{|c|}{ Myocardial infarction (420.0-420.2) } \\
\hline Any years & 157 & 0.87 & $0.74-1.02$ & 0.97 & $0.83-1.14$ & 0.73 & $0.62-0.85$ &.. & .. & .. \\
\hline $0.5-\leq 2$ years & 37 & 0.85 & $0.60-1.17$ & .. & .. &.. & .. & 1.00 &.. & .. \\
\hline $2-10$ years & 43 & 0.75 & $0.54-1.01$ &.. & .. &.. & .. & 0.99 & $0.64-1.54$ &.. \\
\hline$>10$ years & 77 & 0.98 & $0.77-1.22$ & .. & .. & .. & .. & 1.15 & $0.77-1.74$ & $\mathrm{P}=0.37$ \\
\hline \multicolumn{11}{|c|}{ Violent deaths (800-999) } \\
\hline Any years & 74 & 1.14 & $0.90-1.44$ & 1.21 & $0.95-1.52$ & 1.11 & $0.87-1.40$ &.. & .. & .. \\
\hline $0.5-\leq 2$ years & 30 & 1.22 & $0.82-1.74$ & .. & .. & .. & .. & 1.00 & .. & .. \\
\hline $2-10$ years & 33 & 1.40 & $0.96-1.97$ & .. & .. & .. & ... & 1.25 & $0.76-2.06$ & .. \\
\hline$>10$ years & 11 & 0.66 & $0.33-1.19$ & .. & .. & .. & .. & 0.65 & $0.31-1.33$ & $P=0.10$ \\
\hline \multicolumn{11}{|c|}{ Cerebrovascular diseases (330-334) } \\
\hline Any years & 54 & 1.00 & $0.75-1.31$ & 1.14 & $0.86-1.49$ & 0.89 & $0.67-1.17$ &.. & .. & .. \\
\hline $0.5-\leq 2$ years & 14 & 1.09 & $0.60-1.83$ & .. & .. &.. & .. & 1.00 & .. & .. \\
\hline $2-10$ years & 16 & 0.91 & $0.52-1.48$ & .. & .. & .. & .. & 0.94 & $0.46-1.93$ & .. \\
\hline$>10$ years & 24 & 1.02 & $0.66-1.52$ & .. & .. & $\cdot \cdot$ & .. & 0.89 & $0.45-1.77$ & $P=0.78$ \\
\hline \multicolumn{11}{|c|}{ Respiratory diseases (241, 470-527) } \\
\hline Any years & 40 & 1.18 & $0.84-1.61$ & 1.14 & $0.81-1.55$ & .. & .. & .. & .. & .. \\
\hline $0.5-\leq 2$ years & 13 & 1.62 & $0.86-2.77$ & .. & .. & .. & .. & 1.00 & .. & .. \\
\hline $2-10$ years & 13 & 1.17 & $0.62-2.00$ & .. & .. & .. & .. & 0.78 & $0.36-1.69$ &.. \\
\hline$>10$ years & 14 & 0.95 & $0.52-1.59$ & .. & .. & .. & .. & 0.54 & $0.42-1.18$ & $P=0.16$ \\
\hline \multicolumn{11}{|c|}{ Chronic obstructive. lung disease $(241,501-502,526,527.1)$} \\
\hline Any years & 21 & 1.58 & $0.98-2.41$ & 1.43 & $0.89-2.19$ & .. & .. & .. & .. & .. \\
\hline $0.5-\leq 2$ years & 8 & 2.45 & $1.06-4.82$ & .. & .. & .. & .. & 1.00 & .. &.. \\
\hline $2-10$ years & 7 & 1.67 & $0.67-3.43$ & .. & .. & .. & .. & 0.68 & $0.44-1.87$ & .. \\
\hline$>10$ years & 6 & 1.03 & $0.38-2.23$ & .. & .. & .. & .. & 0.32 & $0.10-0.95$ & $P=0.06$ \\
\hline \multicolumn{11}{|c|}{ Mental disorders (300-326) } \\
\hline Any years & 34 & 1.86 & $1.29-2.60$ & 2.37 & $1.64-3.32$ & .. & .. &.. & .. & .. \\
\hline $0.5-\leq 2$ years & 13 & 2.26 & $1.20-3.86$ & .. & .. & .. & .. & 1.00 & .. & .. \\
\hline $2-10$ years & 12 & 2.03 & $1.05-3.55$ & .. & .. & .. & .. & 0.88 & $0.40-1.93$ &.. \\
\hline$>10$ years & 9 & 1.36 & $0.62-2.58$ & .. & .. & .. & .. & 0.59 & $0.25-1-41$ & $P=0.25$ \\
\hline \multicolumn{11}{|c|}{ Diseases of the digestive system (530-587) } \\
\hline Any years & 23 & 1.19 & $0.76-1.79$ & 0.98 & $0.62-1.47$ & .. & .. & .. & .. & .. \\
\hline $0.5-\leq 2$ years & 13 & 2.39 & $1.27-4.09$ & .. & .. & .. & .. & 1.00 & .. & .. \\
\hline $2-10$ years & 5 & 0.77 & $0.25-1.81$ & .. & .. & .. & .. & 0.35 & $0.13-1.00$ &.. \\
\hline$>10$ years & 5 & 0.68 & $0.22-1.58$ & .. & .. & .. & .. & 0.28 & $0.10-0.83$ & $P=0.11$ \\
\hline
\end{tabular}

a Code of the International Classification of Diseases, seventh revision, in parentheses and according to cumulative employment time.

(95\% CI 1.05-2.11), 1.33 (95\% CI 0.85-1.98), and 1.10 (95\% CI 0.55-1.96). The corresponding ratios for cancer of the urinary organs were 1.08 (95\% CI $0.67-1.65)$, 1.06 (95\% CI $0.65-1.65$ ), 1.11 (95\% CI $0.65-1.78$ ), and 0.90 (95\% CI $0.39-1.78)$. The calculation of the standardized incidence ratio for lung cancer among the workers employed for $\geq 10$ years and including a lag time of 20 years gave 1.65 (95\% CI $0.88-2.82$ ) from 13 observed cases when the reference population from northern Sweden was used. The corresponding 
Table 2. Standardized incidence ratios (SIR) and their 95\% confidence intervals (95\% CI) for cancer among the workers in the aluminum industry, calculated with the use of three different reference populations, and the hazard ratios and their $95 \%$ confidence intervals, caluclated with trend tests from Cox regression models using 0.5 to $\leq 2$ years of cumulative employment time as a reference.

\begin{tabular}{|c|c|c|c|c|c|c|c|c|c|c|}
\hline \multirow[t]{2}{*}{ Cancer type a } & \multirow[t]{2}{*}{$\begin{array}{l}\text { Cases } \\
\text { (N) }\end{array}$} & \multicolumn{2}{|c|}{ Northern Sweden } & \multicolumn{2}{|c|}{ Sweden } & \multicolumn{2}{|c|}{$\begin{array}{c}\text { Seven } \\
\text { municipalities }\end{array}$} & \multirow[t]{2}{*}{$\begin{array}{c}\text { Hazard } \\
\text { ratio }\end{array}$} & \multirow[t]{2}{*}{$95 \% \mathrm{Cl}$} & \multirow[t]{2}{*}{$\begin{array}{l}\text { Test for } \\
\text { trend }\end{array}$} \\
\hline & & SIR & $95 \% \mathrm{Cl}$ & SIR & $95 \% \mathrm{Cl}$ & SIR & $95 \% \mathrm{Cl}$ & & & \\
\hline \multicolumn{11}{|l|}{ All types } \\
\hline Any years & 323 & 1.09 & $0.98-1.22$ & 0.97 & $0.86-1.08$ & 1.04 & $0.93-1.16$ &.. & .. & .. \\
\hline $0.5-\leq 2$ years & 107 & 1.22 & $1.00-1.48$ & .. & .. & .. & .. & 1.00 &.. & .. \\
\hline $2-10$ years & 100 & 1.11 & $0.90-1.35$ &.. & .. & .. & .. & 0.83 & $0.63-1.10$ & .. \\
\hline$>10$ years & 116 & 1.06 & $0.88-1.26$ &.. &.$\cdot$ & .. &.$\cdot$ & 0.73 & $0.55-0.96$ & $P=0.07$ \\
\hline \multicolumn{11}{|l|}{ Prostate (177) } \\
\hline Any years & 80 & 1.00 & $0.79-1.25$ & 0.95 & $0.75-1.18$ & 0.96 & $0.77-1.21$ &.. & .. & .. \\
\hline $0.5-\leq 2$ years & 31 & 1.37 & $0.93-1.95$ &.. & .. & .. & .. & 1.00 & .. &.. \\
\hline $2-10$ years & 21 & 0.90 & $0.56-1.38$ & .. &.. &.. & .. & 0.57 & $0.33-1.00$ & .. \\
\hline$>10$ years & 28 & 0.82 & $0.54-1.18$ & $\cdot \cdot$ & $\cdot \cdot$ & $\cdot \cdot$ & $\cdot \cdot$ & 0.50 & $0.29-0.84$ & $P=0.07$ \\
\hline \multicolumn{11}{|l|}{ Lung (162) } \\
\hline Any years & 40 & 1.62 & $1.15-2.20$ & 1.27 & $0.90-1.72$ & 1.48 & $1.06-2.02$ &.. &.$\cdot$ &.$\cdot$ \\
\hline $0.5-\leq 2$ years & 10 & 1.39 & $0.67-2.56$ & .. & .. & .. & .. & 1.00 & .. & .. \\
\hline $2-10$ years & 10 & 1.33 & $0.64-2.45$ & .. & .. & .. & .. & 0.95 & $0.39-2.28$ &.. \\
\hline$>10$ years & 20 & 1.99 & $1.21-3.07$ & .. & .. & .. & .. & 1.31 & $0.60-2.88$ & $P=0.36$ \\
\hline \multicolumn{11}{|c|}{ Urinary organs (181) } \\
\hline Any years & 22 & 1.11 & $0.69-1.68$ & 1.29 & $0.81-1.96$ & 1.02 & $0.64-1.54$ &.. &.. &.. \\
\hline $0.5-\leq 2$ years & 9 & 1.57 & $0.72-2.98$ &.. & .. &.. & .. & 1.00 & .. & .. \\
\hline $2-10$ years & 7 & 1.17 & $0.47-2.40$ & .. & .. & .. & .. & 0.78 & $0.28-2.17$ & .. \\
\hline$>10$ years & 6 & 0.74 & $0.27-1.61$ & .. & .. & .. & .. & 0.48 & $0.16-1.42$ & $P=0.22$ \\
\hline \multicolumn{11}{|l|}{ Colon (153) } \\
\hline Any years & 21 & 1.04 & $0.65-1.60$ & 0.92 & $0.57-1.40$ & 0.97 & $0.60-1.48$ &.. &.$\cdot$ & .. \\
\hline $0.5-\leq 2$ years & 7 & 1.20 & $0.48-2.47$ &.. & .. & .. & .. & 1.00 & .. &.. \\
\hline $2-10$ years & 8 & 1.31 & $0.56-2.58$ & .. & .. & .. & .. & 1.06 & $0.38-2.93$ & .. \\
\hline$>10$ years & 6 & 0.74 & $0.27-1.60$ & .. & .. & .. & .. & 0.63 & $0.21-1.95$ & $P=0.33$ \\
\hline \multicolumn{11}{|c|}{ Central nervous system (193) } \\
\hline Any years & 19 & 1.83 & $1.10-2.86$ & 1.90 & $1.15-2.98$ & 1.85 & $1.11-2.89$ & .. &.. &.. \\
\hline $0.5-\leq 2$ years & 7 & 1.88 & $0.76-3.87$ &.. & .. & .. & .. & 1.00 & .. & .. \\
\hline $2-10$ years & 7 & 2.05 & $0.82-4.23$ & .. & .. & .. & .. & 1.02 & $0.36-2.91$ & .. \\
\hline$>10$ years & 5 & 1.54 & $0.50-3.59$ & .. & .. & .. & .. & 0.67 & $0.20-2.23$ & $P=0.45$ \\
\hline \multicolumn{11}{|c|}{ Head and neck, $(140-148,160-161)$} \\
\hline Any years & 16 & 1.71 & $0.98-2.77$ & 1.25 & $0.71-2.02$ & 1.65 & $0.94-2.68$ &.. &.. & .. \\
\hline $0.5-\leq 2$ years & 5 & 1.74 & $0.56-4.05$ &.. & .. &.. & .. & 1.00 & .. & .. \\
\hline $2-10$ years & 7 & 2.34 & $0.94-4.82$ & .. &.. & .. & .. & 1.44 & $0.46-4.56$ & .. \\
\hline$>10$ years & 4 & 1.14 & $0.31-2.92$ & .. & .. & .. &.. & 0.75 & $0.20-2.84$ & $P=0.40$ \\
\hline \multicolumn{11}{|l|}{ Rectum (154) } \\
\hline Any years & 14 & 1.01 & $0.55-1.70$ & 0.89 & $0.49-1.49$ & 0.93 & $0.51-1.56$ & .. & .. &.$\cdot$ \\
\hline \multicolumn{11}{|l|}{ Kidney (180) } \\
\hline Any years & 12 & 1.07 & $0.55-1.88$ & 1.03 & $0.53-1.79$ & 1.04 & $0.54-1.81$ & .. & .. & .. \\
\hline \multicolumn{11}{|l|}{ Stomach (151) } \\
\hline Any years & 11 & 0.65 & $0.32-1.16$ & 0.81 & $0.40-1.45$ & 0.65 & $0.32-1.16$ & .. & .. & .. \\
\hline \multicolumn{11}{|c|}{ Non-Hodgskins Disease (200) } \\
\hline Any years & 10 & 0.95 & $0.46-1.75$ & 0.91 & $0.44-1.67$ & 0.94 & $0.45-1.72$ & .. & .. & .. \\
\hline Pancreas (157) & & & & & & & & & & \\
\hline Any years & 9 & 0.95 & $0.43-1.80$ & 1.04 & $0.48-1.98$ & 0.92 & $0.42-1.75$ &.$\cdot$ & .. & .. \\
\hline Esophagus (150 & & & & & & & & & & \\
\hline Any years & 8 & 2.58 & $1.12-5.09$ & 1.94 & $0.84-3.83$ & 2.57 & $1.11-5.07$ & .. &.. &.. \\
\hline
\end{tabular}

a Code of the International Classification of Diseases, seventh revision, in parentheses and according to cumulative employment time.

ratio with a lag time of 30 years was $1.43(95 \% \mathrm{CI}$ 0.53-3.12) from six observed cases. The same monotonous decrease in the standardized incidence ratio with longer lag times was observed with either the whole of Sweden or the seven municipalities as the reference population. 


\section{Discussion}

The results of our study showed increased risks of cancer of the central nervous system, head and neck, lungs, and esophagus when the exposed workers were compared with the reference populations. The risk of lung cancer was highest for the workers with the longest employment at the smelter. The increased mortality due to chronic obstructive lung disease, mental disorders, and diseases of the digestive system was statistically significant, but only for the short-term workers. Trend tests carried out with the Cox regression did not verify any associations with cumulative employment time.

Unlike most studies in the aluminum industry, we did not find an association between bladder cancer and work in the aluminum industry (8, 16-19). Perhaps the absence of any association is due to smoking, which implies that the real risk of lung cancer would be higher than observed in our study if we had been able to control for smoking. Pirastu et al (26) stated that smoking accounts for about $50 \%$ of all cases of bladder cancer in western countries. The difference in the standardized incidence ratio, depending on the choice of reference population, also implies that urinary organs could be sensitive to confounding effects. Rønneberg et al (27) suggested a latency period of $\geq 30$ years for bladder cancer, but, in our study, the estimated standardized incidence ratios were lowest when we incorporated a lag time of 30 years.

Results from prior studies of lung cancer in the aluminum industry have suggested a positive association, although not a conclusive one. In a meta-analysis, Armstrong et al (22) concluded that lung cancer is associated both with PAH and aluminum production works, with similar average relative risks of 1.20 and 1.16 , respectively. In a later study, Spinelli et al (17) verified an association between work in the aluminum industry and lung cancer. Norwegian studies, however, have not confirmed the increased risk of lung cancer among aluminum industry workers (8, 13, 18, 27), although in an earlier study, Rönneberg \& Andersen (28) found an excess risk when comparing observed rates with the rates of the local population. In our study, the estimated risk of lung cancer was highest among those working at the plant for $\geq 10$ years; this finding provides evidence of a risk associated with working in the smelter. However, our study lacked the power to verify statistically, using the Cox model, any excess risk for long-term workers. Our study has long follow-up times, and, therefore, it was possible to test for long latency times, something that is especially important when lung cancer data are analyzed. Archer et al (29) found that the latency period for uranium miners was about 25 years for nonsmokers and 19 years for smokers. Norwegian studies by Romunstad and Rønneberg and their coworkers (8, 13, $18,27,28)$ are the only cohort studies on aluminum smelters that have tested for latency times as long as 30 years. In our study, the relative risk of lung cancer did not increase with longer lag times, as would be expected if the date of first employment had correlated with the onset of exposure, leading to a higher risk. Smoking could explain the elevated risk of lung cancer, although cancer of the urinary organs, which is highly correlated with smoking, decreased with longer employment times. The lower risk identified when the Swedish population was used as reference, compared with the population of northern Sweden or that of the seven municipalities, has to be taken into consideration when the results for lung cancer are evaluated. Lifestyle factors such as smoking are likely to explain differences in the reference rates.

In previous studies, cancer of the central nervous system has exhibited weak or no associations with work in the aluminum industry. Studies by Spinelli et al (17) and Mur et al (10) presented nonsignificant, but elevated relative risks for brain cancer. Rønneberg et al (27) did not find an association with cancer of the central nervous system. Our study offers support for the hypothesis that there is an association. The rates for cancer of the head and neck were elevated when compared with the rates of the reference population from northern Sweden, but the standardized ratio was not statistically significant. No corresponding findings have been published previously.

Generally, studies of mortality among workers in the aluminum industry have indicated lower overall mortality rates than for the reference populations. In our study, the overall standardized mortality ratio was slightly above unity in relation to all of the three reference populations. The "healthy worker effect" suggests that mortality closer to the start of employment should be lower than in the general population, but, with our long follow-up times, the influence of the "healthy worker effect" could be expected to be minimized. For the short-term workers, statistically significant higher risks of mortality were observed for chronic obstructive lung disease, mental disorders, and diseases of the digestive system, and the standardized mortality ratio for diseases of the digestive system increased as the lag time increased. Of the 34 deaths associated with mental disorders, 27 were related to alcohol, a finding that suggests an elevated consumption of alcohol among the short-term workers. With respect to the incidence of cancer, all risks except that for lung cancer were the lowest for the workers who had been employed for $\geq 10$ years. The negative relationship between employment duration and mortality and cancer incidence agrees with the results of studies by Rønneberg et al (27) and Rönneberg \& Andersen (28). One possible contributory factor to the higher risks among the short-term workers could be that the worksites associated with higher risks have higher staff turnover rates than sites with lower 
risks. The "survivor population effect" described by Fox \& Collier (30) also helps to explain the higher risk among the short-term workers. The survivor population effect means that healthier workers are more likely to stay in the workforce than persons with poorer health. Furthermore, a Danish study found that preemployment hospitalization predicts length of employment (31). The survivor population phenomenon is a problem when the cumulative exposure is evaluated on the basis on length of employment as it dilutes true underlying associations with exposure.

One strength of our study is that it contained long follow-up times with, on the average, 52 years of follow-up for mortality and 47 years of follow-up for the incidence of cancer; these represent the longest follow-up data for aluminum smelter workers published to date. The old age of the cohort means that we have a representation of work years in the cohort from before attention on work environment issues was as strong as it is today. We also have a fraction of the cohort with very long follow-up times, and therefore the diseases with long latency times could be covered within the time-span of this study. With an average age of 30 years at first employment and an average time of employment of 8 years, increased risks for cancer sites with long latency times such as lung cancer and bladder cancer may not show until 65-70 years of age. Another scenario is that exposure from the factory works as an effect modifier for some other factors (eg, smoking). Then elevated risks could show up at younger ages, as the onset of smoking may be earlier in life. Previous cohort studies on primary aluminum smelter workers using standardized ratios have based their results on only one reference population (7, 8, 11-13, 17, 18, 27, 28, 32). In Sweden, we have access to reliable records on mortality and the incidence of cancer, including information on the place of residence, making it possible to conduct comparisons with expected rates using different neighboring regions. This study shows that, for some outcomes, the choice of the reference population had an important influence on the level of the estimated risks.

The results of this study support those of previous studies that indicated an excess risk of lung cancer among aluminum smelter workers, the highest risk occurring among workers employed for $\geq 10$ years. In contrast to most studies, an elevated risk of cancer of the central nervous system was observed in our study. Our study did not identify any association with cancer of the urinary organs.

\section{References}

1. Benke G, Abramson M, Sim M. Exposures in the alumina and primary aluminium industry: an historical review. Ann Occup
Hyg. 1998;42(3):173-89.

2. Höflich B, Weinbruch S, Theissmann R, Gorzawski H, Ebert $\mathrm{M}$, Ortner $\mathrm{H}$, et al. Characterization of individual aerosol particles in workroom air of aluminium smelter potrooms. J Environ Monit. 2005;7(5):419-24.

3. Thomassen Y, Koch W, Dunkhorst W, Ellingsen D, Skaugset $\mathrm{N}$, Jordbekken L, et al. Ultrafine particles at workplaces of a primary aluminium smelter. J Environ Monit. 2006;8(1):12733.

4. Taiwo OA, Slade MD, Cantley LF, Fiellin MG, Wesdock JC, Bayer FJ, et al. Beryllium sensitization in aluminum smelter workers. J Occup Environ Med. 2008;50(2):157-62.

5. International Agency for Research on Cancer (IARC). Polynuclear aromatic compounds, part 3: industrial exposures in aluminium production, and iron and steel founding. Lyon: IARC; 1984. p 37-64.

6. International Agency for Research on Cancer (IARC). Complete list of agents evaluated and their classification [homepage on the Internet]. Lyon (France): IARC [updated 12 May 2008; cited 02 October 2008]. Available from: http://monographs. iarc.fr/ENG/Classification/index.php.

7. Rockette HE, Arena VC. Mortality studies of aluminium reduction plant workers: potroom and carbon departments. J Occup Med. 1983;25(7):549-57.

8. Romundstad P, Haldorsen T, Andersen A. Cancer incidence and cause specific mortality among workers in two Norwegian aluminum reduction plants. Am J Ind Med. 2000;37:175-83.

9. Spinelli JJ, Band PR, Svirchev LM, Gallagher RP. Mortality and cancer incidence in aluminium reduction plant workers. J Occup Med. 1991;33(11):1150-5.

10. Mur JM, Moulin JJ, Meyer-Bisch C, Massin N, Coulon JP, Loulergue J. Mortality of aluminium reduction plant workers in France. Int J Epidemiol. 1987;16(2):257-64.

11. Gibbs GW. Mortality of aluminium reduction plant workers, 1950 through 1977. J Occup Med. 1985;27(10):761-70.

12. Milham S. Mortality in aluminium reduction plant workers. $\mathbf{J}$ Occup Med. 1979;21(7):475-80.

13. Romundstad P, Haldorsen T, Andersen A. Lung and bladder cancer among workers in a Norwegian aluminium reduction plant. Occup Environ Med. 2000;57:495-9.

14. Friesen MC, Demers PA, Spinelli JJ, Lorenzi MF, Le ND. Comparison of two indices of exposure to polycyclic aromatic hydrocarbons in a retrospective aluminium smelter cohort. Occup Environ Med. 2007;64:273-8.

15. Rönneberg A. Epidemiologic evidence of cancer in aluminium reduction plant workers. Am J Ind Med. 1992;22:573-90.

16. Tremblay C, Armstrong B, Thériault G, Brodeur J. Estimation of risk of developing bladder cancer among workers exposed to coal tar pitch volatiles in the primary aluminum industry. Am J Ind Med. 1995;27:335-48.

17. Spinelli JJ, Demers PA, Le ND, Friesen MD, Lorenzi MF, Fang $\mathrm{R}$, et al. Cancer risk in aluminium reduction plant workers (Canada). Cancer Causes Control. 2006;17:939-48.

18. Romundstad P, Andersen A, Haldorsen T. Cancer incidence among workers in six Norwegian aluminum plants. Scand J Work Environ Health. 2000;26(6):461-9.

19. Clavel J, Mandereau L, Limasset J-C, Hémon D, Cordier S. Occupational exposure to polycyclic aromatic hydrocarbons and the risk of bladder cancer: a French case-control study. Int J Epidemiol. 1994;23(6):1145-53.

20. Thériault G, Tremblay C, Cordier S, Gingras S. Bladder cancer in the aluminium industry. Lancet. 1984:947-50.

21. Armstrong B, Tremblay C, Baris D, Thérialult G. Lung cancer mortality and polynuclear aromatic hydrocarbons: a case-co- 
hort study of aluminum production workers in Arvida, Quebec, Canada. Am J Epidemiol. 1994;139(3):250-62.

22. Armstrong B, Hutchinson E, Unwin J, Fletcher T. Lung cancer risk after exposure to polycyclic aromatic hydrocarbons: a review and meta-analysis. Environ Health Perspect. 2004;112(9):970-8.

23. Gallagher RP, McBride ML, Band PR, Spinelli JJ, Threlfall WJ, Tamaro S. Brain cancer and exposure to electromagnetic fields. J Occup Med. 1991;33(9):944-5.

24. Carstensen U, Yang K, Levin J-O, Östman C, Nilsson T, Hemminki K, et al. Genotoxic exposures of potroom workers. Scand J Work Environ Health. 1999;25(1):24-32.

25. Breslow N, Day N. Statistical methods in cancer research, vol 2: the design and analysis of cohort studies. Oxford: University press; 1988.

26. Pirastu R, Iavarone I, Comba P. Bladder cancer: a selected review of the epidemiological literature. Ann Ist Super Sanità. 1996;32(1):3-20.

27. Rønneberg A, Haldorsen T, Romundstad P, Andersen A. Occupational exposure and cancer incidence among workers from an aluminum smelter in western Norway. Scand J Work Environ Health. 1999;25(3):207-14.

28. Rönneberg A, Andersen A. Mortality and cancer morbidity in workers from an aluminium smelter with prebaked carbon anodes part II: cancer morbidity. Occup Environ Med. 1995;52:250-4.

29. Archer V, Coons T, Saccomanno G, Hong D. Latency and the lung cancer epidemic among United States uranium miners. Health Phys. 2004;87(5):480-9.

30. Fox A, Collier P. Low mortality rates in industrial cohort studies due to selection of work and survival in the industry. Br J Prev Soc Med. 1976;30(4):225-30.

31. Kolstad HA, Olsen J. Why do short term workers have high mortality? Am J Epidemiol. 1999;149(4):347-52.

32. Rönneberg A. Mortality and cancer morbidity in workers from an aluminium smelter with prebaked carbon anodes, part III: mortality from circulatory and respiratory diseases. Occup Environ Med. 1995;52:255-61.

Received for publication: 9 May 2008 